\title{
Thresholds are in the eye of the beholder: plants and wildlife respond differently to short-term cattle corrals
}

\author{
Kari E. Veblen ${ }^{1,2,4}$ and Lauren M. Porensky ${ }^{2,3}$ \\ ${ }^{1}$ Department of Wildland Resources and Ecology Center, Utah State University, Logan, Utah 84322 USA \\ ${ }^{2}$ Mpala Research Centre, P.O. Box 555, Nanyuki, Kenya \\ ${ }^{3}$ USDA-ARS Rangeland Resources and Systems Research Unit, Fort Collins, Colorado 80526 USA
}

Citation: Veblen, K. E., and L. M. Porensky. 2019. Thresholds are in the eye of the beholder: plants and wildlife respond differently to short-term cattle corrals. Ecological Applications 00(00):e01982. 10.1002/eap.1982

Abstract. Rangelands are governed by threshold dynamics, and factors such as drought, wildfire, and herbivory can drive change across thresholds and between ecological states. Most work on this topic has focused on shifts in a single response variable, vegetation, and little research has considered how to reconcile responses of more than one variable to determine whether a system has undergone a genuine state change. In sub-Saharan Africa, mobile overnight livestock corrals (bomas) can be used by managers to precipitate ecological transitions from areas dominated by bare ground to productive ecosystem hotspots (glades) that are attractive to wild herbivores. We asked how long bomas must be occupied by cattle before undergoing a state change, considering both plant and animal response variables, to glade ecosystem hotspots. We tested five durations of boma occupation: $0,4,7,14$, and 28 days. Each treatment was replicated five times, and we assessed vegetation as well as herbivore dung (as a proxy of use) at multiple time points over $3 \mathrm{yr}$ following boma abandonment. Vegetation in 7-, 14-, and 28-d boma duration treatments appeared to undergo a complete transition to glade-like plant communities, whereas the shortest 4-d treatment had not converted to a glade plant community by year 3. Wildlife responses appeared to lag behind vegetation responses, with transitions to glade-like herbivore use occurring only in the longest duration (14- and 28d) treatments. Our results show that different response variables, when considered individually, may provide incomplete or misleading information about state changes. Although shorteroccupied bomas might be effective for reducing bare ground, they may not attract enough wild herbivores to constitute crossing into an alternative state. Understanding threshold dynamics associated not only with vegetation responses but with a broader suite of response variables is challenging, but will provide a more complete representation of ecosystem function and greater opportunity for more successful ecosystem management.

Key words: alternative stables states; restoration; savanna; state-and-transition models; targeted grazing; tipping points.

\section{INTRODUCTION}

An understanding of ecological thresholds is increasingly being recognized as vital to successful ecosystem management (Stringham et al. 2003, Briske et al. 2005, Scheffer 2009, Bagchi et al. 2013, Kachergis et al. 2014), and scientists and managers have long recognized that rangelands in particular can be governed by threshold dynamics (Westoby et al. 1989, van de Koppel et al. 1997, Briske et al. 2003, 2005). Factors such as drought, wildfire, fire suppression, and livestock use drive change across thresholds and between ecological states (Milton and Hoffman 1994, Courtois et al. 2004, Briske et al. 2005, Miller et al. 2011, Young et al. 2014, Porensky

Manuscript received 5 February 2019; revised 10 June 2019; accepted 8 July 2019. Corresponding Editor: Adam T. Ford.

${ }^{4}$ E-mail: kari.veblen@usu.edu et al. 2018), though resilience to these disturbances also is common in rangeland ecosystems (Fuhlendorf et al. 2001, Valone et al. 2002, Bestelmeyer et al. 2013, Ellsworth et al. 2016, Porensky et al. 2016). Across ecosystems, the intensity, frequency, and duration of disturbance influence when and whether thresholds are crossed (Sasaki et al. 2008, Twidwell et al. 2013, Ratajczak et al. 2014), or the timescale over which reversibility occurs (Augustine et al. 2014). Understanding how disturbance properties relate to threshold dynamics is key to managers' ability to prevent or reverse undesirable transitions, or to precipitate transitions to desirable states.

Most studies that have identified alternative states, thresholds, and tipping points in rangeland systems have focused on shifts or differences in vegetation (e.g., Bagchi et al. 2013, Augustine et al. 2014, Kachergis et al. 2014, Young et al. 2014, Porensky et al. 2016), and 
researchers have identified the lack of work on other ecosystem attributes or services as an ongoing challenge (Bestelmeyer et al. 2017). Recent research has begun to refine state-and-transition models via inclusion of functional attributes (e.g., Miller et al. 2011, Tipton et al. 2018) and wildlife responses (e.g., Bruegger et al. 2016). However, little research has simultaneously considered shifts in more than a single response variable or how to interpret a suite of response variables with respect to whether a system has functionally crossed a threshold to a genuine alternative state. In some cases, different attributes may move toward thresholds at different rates. For example, assessment of a single attribute, such as vegetation, may suggest that a functional threshold has been crossed. However, a different attribute measured in the same system, such as wildlife use patterns that are expected to accompany vegetation change, may indicate that a threshold has not been crossed. One would therefore conclude that a genuine, effectively permanent, state change has not yet occurred.

We studied thresholds and tipping points for plant and wildlife response variables in a sub-Saharan African rangeland, where overnight corralling of livestock can be used to precipitate ecological transitions from areas dominated by bare ground to productive "ecosystem hotspots" (Porensky and Veblen 2015). In many regions of sub-Saharan Africa, traditional thorn-fence cattle corrals (bomas) placed on sites ranging from bare- to grass- to tree-dominated, develop into hotspots of unique vegetation composition, high nutrients, and increased use by wild herbivores (Stelfox 1986, Blackmore et al. 1990, Reid and Ellis 1995, Augustine 2003a, van der Waal et al. 2011, Donihue et al. 2013, Ford et al. 2014, Chikorowondo et al. 2017, Marshall et al. 2018, Otieno et al. 2019). In central Kenya, abandoned boma sites develop into treeless, highly productive "glades" that persist for at least $50 \mathrm{yr}$ (Augustine 2003a, Veblen 2012). Large herbivore wildlife is attracted to glade sites because they provide highly nutritious forage and their lack of tree cover enhances predator detection (Riginos and Grace 2008, Ford et al. 2014, Riginos 2015). In turn, herbivores maintain the vegetation and high nutrient status of glades through feedbacks with the plant community (e.g., Augustine 2003a, Veblen and Young 2010, Porensky and Veblen 2012, Veblen 2012). Thus, traditional glades persist for decades in an apparently semi-permanent, self-sustaining state. The minimum amount of livestock disturbance required to create persistent functional glades that are both characterized by glade vegetation and attractive to wild herbivores is not known. Identifying this threshold of livestock disturbance is key to understanding multi-attribute state changes and managing for multiple objectives (e.g., livestock production and wildlife conservation) in these highly biodiverse agroecosystems (Young et al. 2018).

Fortunately, recent technological developments have enabled manipulative experiments that can pinpoint thresholds associated with glade creation. In central
Kenya, livestock managers have developed metal-fenced "mobile" bomas, which are both better at protecting livestock against predation and more portable than their traditional thorn-fence counterparts (Porensky and Veblen 2015). Their portability allows managers to intentionally place mobile bomas in degraded bare areas to fertilize and restore vegetation, or to use mobile bomas to create strategically located wildlife hotspots (e.g., Ng'weno et al. 2019). Traditional (thorn fence) bomas are typically kept in place for months to years at a time because they require arduous tree harvesting $(>1,000$ stems for a single boma). In contrast, mobile bomas are typically kept in place for much shorter periods, and some managers move their bomas as often as once or twice per week. In central Kenya, Porensky and Veblen (2015) showed that a mobile boma kept in place for one month was sufficient to create a glade-like feature that attracted wild herbivores and provided palatable forage for livestock. In southern Africa, bomas kept in place for $7 \mathrm{~d}$ increased the proportion of palatable grasses but produced only a short-term wildlife response (Huruba et al. 2017, 2018). Presumably, below a minimum duration of occupation, short-term mobile bomas will not capture enough cattle-derived nutrients and seeds to convert to a glade-like vegetation state, even given sufficient moisture. Similarly, it is possible that only longer durations of boma occupation provide the forage attributes necessary to also attract wild herbivores and push the site over a functional threshold and into an effectively permanent ecosystem hotspot state.

Using a broad-scale manipulative experiment, we asked how long boma sites must be occupied to (1) convert to glade hotspot vegetation after boma abandonment and (2) generate wild herbivore preference for the site. In bomas used for one week or less, we expected vegetation to recover quickly from cattle impact, but because these sites did not receive much fertilization from cattle dung, we expected that they would not convert to palatable glade vegetation. We expected the resultant low-quality glades to attract few wild herbivores and disappear after a few months. By contrast, we expected longer occupancy times to initiate dramatic changes in herbaceous species composition, and we expected sites occupied for longer to attract more wildlife due to highly palatable forage.

\section{Methods}

\section{Study site}

The study site is located on the Mpala Conservancy $\left(0^{\circ} 17^{\prime} \mathrm{N}, 36^{\circ} 52^{\prime} \mathrm{E} ; 1,800 \mathrm{~m}\right.$ above sea level) in Laikipia, Kenya. During our data collection period, April 2011 through July 2014, rainfall at the site averaged $745 \pm 117$ (mean $\pm \mathrm{SE}$ ) mm/calendar year (range 443$1,016 \mathrm{~mm}$ ) and exhibited a weakly trimodal pattern, with major peaks in April-May $(204 \pm 27 \mathrm{~mm} /$ month $)$ and October-November $(103 \pm 28 \mathrm{~mm} / \mathrm{month})$ and a 
minor peak in August $(89 \pm 25 \mathrm{~mm} / \mathrm{month})$. Our study was located in the transition zone between two dominant soil types: "black cotton" soils, poorly drained vertisols with high $(>50 \%)$ clay content (Ahn and Geiger 1987), and red sandy soils (Ferric and Chromic Luvisols) averaging $15 \%$ clay and $74 \%$ sand. We dug soil cores to $50 \mathrm{~cm}$ and, based on field tests of soil texture, selected only sites with textures ranging from sandy clay loam to sandy loam. The plant community in black cotton soils is characterized by a near monoculture of Acacia drepanolobium in the overstory while the understory is characterized by nearly continuous cover dominated ( $>90 \%$ cover) by five perennial grasses (Young et al. 1998). The red sandy soils community is characterized as open Acacia brevispica thicket (Taiti 1992) with an understory characterized by patches of bare ground interspersed with a diversity of grasses and forbs (Augustine 2003b). The vegetation community in the transition zone, where our study plots were located, is intermediate between the two. We intentionally located study plots on relatively flat areas that were dominated by bare ground and where reestablishment of vegetation was desired by managers. Higher coverage of bare ground than would be expected under reference conditions likely was due to a combination of historic herbivore use and landscape factors.

The Mpala Conservancy is managed for both wildlife conservation and livestock production. Cattle are stocked at low to moderate densities $(0.10-0.14$ cattle/ ha). Wild herbivores include elephant (Loxodonta africana Blumenbach), giraffe (Giraffa camelopardalis L.), Cape Buffalo (Syncerus caffer Sparrman), eland (Taurotragus oryx Pallas), zebra (Equus burchelli Gray), Grevy's zebra (Equus grevyi Oustalet), oryx (Oryx gazella beisa L.), hartebeest (Alcelaphus buselaphus Pallas), impala (Aepyceros melampus Lichtenstein), Grant's gazelle (Gazella grantii Brooke), Thomson's gazelle (Gazella thomsonii Günther), warthog (Phacochoerus africanus Gmelin), dikdik (Madoqua guentheri Thomas), and hare (Lepus spp.). Wildlife in this region are present year-round and do not undergo large seasonal migrations.

\section{Experimental design}

We used a randomized complete block design, locating five $200 \times 200 \mathrm{~m}$ sites on relatively bare areas within each of five blocks $(n=25)$. Within each block, one site was randomly designated as an unmanipulated control. Metal mobile bomas were installed at the other four sites within the block, and each boma was randomly assigned to one of four boma duration treatments: $4 \mathrm{~d}, 7 \mathrm{~d}, 14 \mathrm{~d}$, and $28 \mathrm{~d}$. To capture variability in weather relative to timing of boma use, we installed three blocks in April 2011 and two blocks in October 2011. In both cases, installation was timed to occur at the beginning of a rainy season, though October sites received twice as much rainfall during and immediately following boma installation than did the April sites (342 $\mathrm{mm}$ in October and November vs. $161 \mathrm{~mm}$ in April and May). Each boma site contained one centrally located boma, which held cattle each night. To create the different boma occupation treatments, within each of the two (April and October) time blocks, five herds of $\sim 100$ cows (in April) or $\sim 84$ cows (in October) were randomly assigned to bomas and rotated such that treatments within a given block began at similar times (Appendix S1: Table S1). This herd size is standard for the region. Bomas averaged $19.6 \pm 0.25 \mathrm{~m}$ (mean $\pm \mathrm{SE}$ ) in diameter, with animals packed tightly to minimize predation risk (Porensky and Veblen 2015). Sites within a block were at least $250 \mathrm{~m}$ apart, and all sites were more than $100 \mathrm{~m}$ from any existing glades or bomas to minimize interference with these features (Porensky 2011). Blocks also were at least $250 \mathrm{~m}$ apart, with blocking based on similarities in soil texture, landscape position, and location relative to physical features such as roads.

\section{Data collection}

All 25 sites were monitored before initiating the experiment and at multiple time points after mobile boma abandonment (Table 1). At each site, we established four transects that radiated outward from points located $2.5 \mathrm{~m}$ away from the center of each boma or control site (Fig. 1). For completely flat sites, the first transect was oriented in a random cardinal direction and all other transects were oriented at $90^{\circ}$ intervals from the first. For slightly sloped sites, two transects were oriented parallel to the slope and the other two were oriented perpendicular to the slope. At each monitoring date, we visually estimated understory plant cover by species in four $1 \times 1 \mathrm{~m}$ quadrats placed at the beginning of each transect (i.e., $2.5 \mathrm{~m}$ from boma center); this was done only in two quadrats for baseline measurements in the three April 2011 blocks. We estimated canopy cover (i.e., plant material that would intercept a raindrop) rather than canopy closure (i.e., polygons drawn around plant canopies). For portions of the quadrat with no foliar or basal vascular plant cover, we estimated other cover types (e.g., lichen, moss, litter or dung, and bare ground). We used the same, experienced observers for all sample periods and calibrated among observers before and several times during each sampling period.

We estimated livestock and wild herbivore use by counting herbivore dung piles (and immediately crushing them to avoid double counting) along $8 \mathrm{~m}$ wide belts ( $4 \mathrm{~m}$ wide for hares) along two of the four vegetation transects at each boma or control site (Fig. 1). Dung counts provide reliable estimates of relative use for a given species at a given site (Barnes 2001). To estimate usage of inside-boma areas, we tallied dung by species for $5 \mathrm{~m}$ along each belt (Fig. 1) for each of the first three sampling periods. Thus, the sampling area was $40 \mathrm{~m}^{2} /$ transect for ungulates and $20 \mathrm{~m}^{2} /$ transect for hares; dung that occurred in the $2.25 \mathrm{~m}^{2}$ of overlap at the start 
TABLE 1. Field sampling schedule for vegetation and dung data collection.

\begin{tabular}{|c|c|c|}
\hline \multirow[b]{2}{*}{ Sample date } & \multicolumn{2}{|c|}{ Time block } \\
\hline & Blocks 1-3 & Blocks 4-5 \\
\hline Apr 2011 & 0 month $(0$ month $)$ & \\
\hline Sep 2011 & 5 month (5 month) & \\
\hline Oct 2011 & & 0 month $(0$ month $)$ \\
\hline Jul/Aug 2012 & $1-1.5 \mathrm{yr}(15 / 16$ month $)$ & \\
\hline Sep 2012 & & $1-1.5 \mathrm{yr}(11 \mathrm{month}) \dagger$ \\
\hline Mar 2013 & & $1-1.5 \mathrm{yr}(17$ month $) \ddagger$ \\
\hline Jul $2013 \S$ & $2 \mathrm{yr}$ (27 month) & $2 \mathrm{yr}(21$ month $)$ \\
\hline Aug 2014 & $3 \mathrm{yr}$ (38 month) & $3 \mathrm{yr}$ (32 month) \\
\hline
\end{tabular}

Notes: Treatments in experimental blocks $1-3$ and 4-5 were initiated at different times, but treatments were assessed in similar post-establishment time blocks (e.g., 1-1.5 yr after treatment initiation). Numbers in parentheses indicate months since boma abandonment and were included as continuous variables in the overall statistical models. Any significant treatment $\times$ time interactions were investigated within time blocks. These represent all available data on vegetation community composition and dung density from the first $3 \mathrm{yr}$ of the experiment; absence of data in some time periods was due to lack of available personnel.

$\dagger$ Block 4 only.

$\$$ Block 5 only.

$\S$ Vegetation only.

of the two belts was only counted once. For the final 3yr sampling period, we estimated livestock and wild herbivore use by exhaustively sampling a $6 \mathrm{~m}$ radius circular area centered on the boma (or control) centroid.

\section{Data analysis}

Community-scale analyses. -We performed separate nonmetric multidimensional scaling (NMDS) analyses

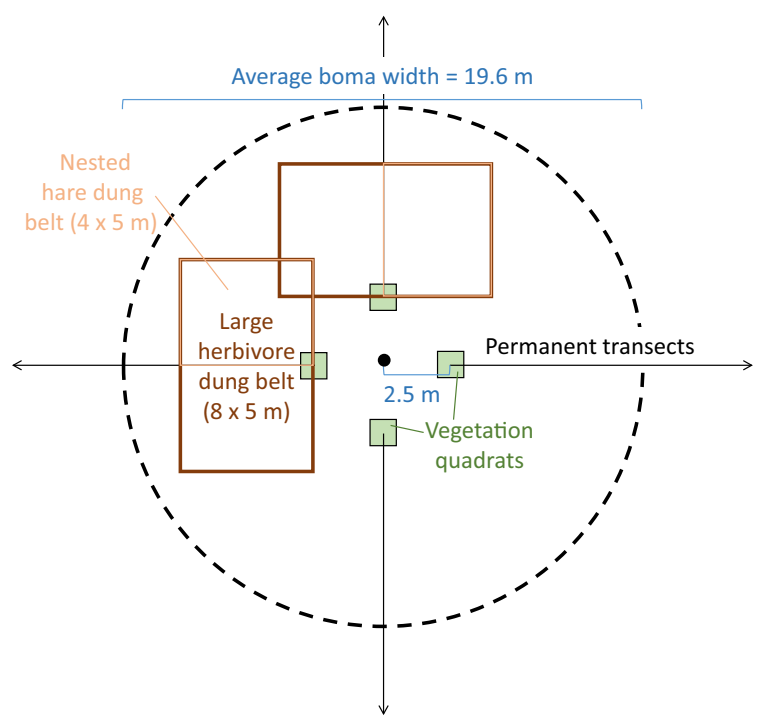

FIG. 1. Sampling design for vegetation and dung measurements applied to all 0-, 4-, 7-, 14-, and 28-d boma sites. on plant community and herbivore community data sets. To prepare data for NMDS analysis, we excluded species that occurred in $<5 \%$ of all samples (i.e., all plots over all sample periods) (sensu Harrison et al. 2010, Alday et al. 2013). This reduced the data set from 107 to 61 taxa for plants, and from 18 to 13 taxa for herbivores. For plants, we analyzed relative cover, which, for a given species, is its total percent cover in a plot divided by the total percent cover summed across all species within that plot in that sample period. Relative cover provides an index of the contribution of each species to the herbaceous community while controlling for differences in total biomass due to experimental treatments and interannual variations in rainfall. For dung, we standardized counts across species and sampling periods. We divided the number of dung piles per hectare found for each species within each plot by the maximum number of piles found for that species within a given block and sampling time period. This enabled comparisons across species and across time periods. We used the meta-MDS function in the vegan library (version 2.5-1; Oksanen et al. 2018) for R (version 3.3.0; R Core Team (2016)) to perform separate NMDS analyses for plant communities during baseline, $2 \mathrm{yr}$ post-treatment, and $3 \mathrm{yr}$ post-treatment time periods and herbivore communities during baseline, $1-1.5 \mathrm{yr}$ post-treatment and $3 \mathrm{yr}$ post-treatment time periods (Table 1; six separate analyses; permutations $=999$ ). We used Bray-Curtis (Sørensen) dissimilarity matrices, and all but the plant baseline and dung 1-1.5 yr post-treatment matrices were Wisconsin square-root transformed to improve fit.

To examine differences in plant and herbivore community composition among treatments, we also performed permutational multivariate analysis of variance (perMANOVA) tests on Bray-Curtis (Sørensen) dissimilarity matrices. We used the Adonis function in vegan ( $\mathrm{R}$ version 2.5-1) to test the simultaneous response of all species to block (five levels) and boma duration treatment (five levels) during each of three sampling periods for plants and three sampling periods for herbivores (six separate analyses; permutations $=999$ ). For this and other analyses described below, we treated boma duration as a categorical variable because we expected the relationship between occupation time and response variables to be non-linear (e.g., a step function). The Adonis function uses sequential evaluation of "block" prior to "treatment," which is similar to treating block as a random factor.

Functional group and species richness analyses.-Absolute (rather than relative) plant cover data and standardized herbivore dung data were analyzed by functional group using linear mixed models with Gaussian distributional assumptions in JMP (12.0.1, SAS Institute, Cary, North Carolina, USA). Separate analyses were conducted for each of 10 plant response variables (total plant cover, grass cover, forb cover, cover of C. plectostachyus [a characteristic glade grass], cover of other perennial grasses, cover of short-lived [annual or 
biennial] grasses, litter + dung cover, rock cover, bare ground, and species richness per square meter) and three herbivore response variables (all wild ungulates, livestock [cow, camel, and sheep], and hares). Fixed factors included boma duration treatment (categorical), months since boma abandonment (continuous; Table 1), and the interaction between these two predictors. To account for spatial and temporal non-independence, random factors included block and plot nested within block. A compound symmetry covariance structure was used to account for repeated measurements. If the interaction between treatment and time was significant, we conducted separate analyses to ask whether treatments were significantly different within each sampling period (time block; Table 1) for which we had data from three or more blocks. For plant responses, time blocks were 0 months, 5 months, $1-1.5,2$, and 3 yr. For herbivores, time blocks were 0,5 months, $1-1.5$, and $3 \mathrm{yr}$. Within each time block, treatment was included as a fixed factor and block was included as a random factor. Response variables were transformed or variance-weighted when necessary to meet model assumptions. Results are reported as means $\pm \mathrm{SE}$.

\section{Results}

\section{Plant community change}

For all sample periods, NMDS ordinations required three axes to achieve stress values $<0.15$. During the baseline time period, boma duration treatment had no significant effects on plant community structure (Fig. 2a, b, NMDS stress $=0.09$, nonmetric fit $R^{2}=0.991 ; \quad$ PerMANOVA $\quad F_{4,14}=0.90, \quad P=0.6$ ),
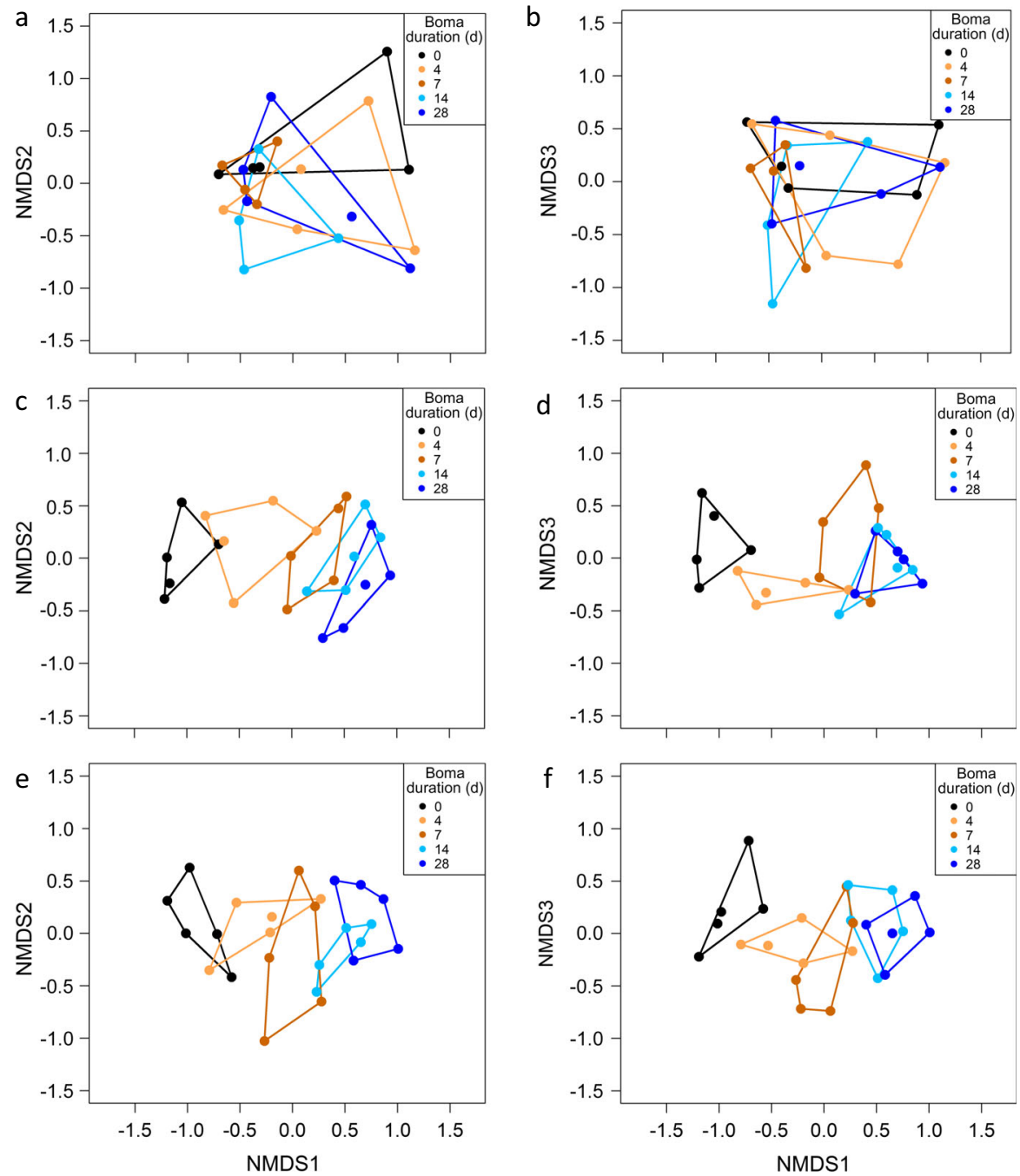

FIG. 2. Nonmetric multidimensional scaling (NMDS) axis scores and convex hulls for different boma duration (0-, 4-, 7-, 14-, and 28-d) treatment plots for vegetation communities during $(\mathrm{a}, \mathrm{b})$ baseline, $(\mathrm{c}, \mathrm{d}) 2 \mathrm{yr}$ post-treatment, and (e, f) 3 yr post-treatment time periods. See Appendix S2: Fig. S1 for displays of axes 2 vs. 3. 
though different blocks did support slightly different communities $\left(F_{4,14}=1.58, P=0.05\right)$. Sites and blocks did vary in community composition during baseline sampling, and this variation was driven by abundances of Barleria spinosa (a common subshrub), multiple Eragrostis grass species, multiple annual Aristida grass species, Cynodon dactylon (a perennial grass), the perennial forbs Aspilia pleuriseta and Melhania velutina, and several annual forbs (Fig. 3, Appendix S2: Table S1).

For the yr 2 sampling period, both boma duration treatment and block significantly influenced plant community composition (PerMANOVA boma duration $F_{4,16}=3.34, P=0.001$; block $F_{4,16}=1.61, P=0.02$ ). Boma duration treatments were clearly separated along NMDS axis 1 (Fig. 2c, d, NMDS stress $=0.11$, nonmetric fit $\left.R^{2}=0.987\right)$. Control treatments were associated with low values along axis 1 , while boma treatments had increasingly higher scores along this axis as duration of boma occupation increased. Species that had significant, positive correlations with axis 1 included the perennial grass C. plectostachyus along with several forbs, including Chenopodium schraderianum, Commelina spp., and Solanum nigrum (Fig. 3, Appendix S2: Table S1). A wide variety of species were negatively correlated with axis 1, many of which were common during the 2011 baseline sampling effort (Appendix S2: Table S1). NMDS axes 2 and 3 were not strongly associated with boma duration treatments (Fig. 2c, d; Fig. 3).

During the 3-yr post-treatment time period, both boma duration treatment and block significantly influenced plant community composition (PerMANOVA boma duration $F_{4,16}=2.64, P=0.001$; block $\left.F_{4,16}=1.82, P=0.007\right)$. As in year 2 , boma duration treatments were clearly separated along NMDS axis 1 (Fig. 2e, f, NMDS stress $=0.13$, nonmetric fit $R^{2}=0.984$ ). Control treatments were associated with low values along axis 1 , while boma treatments had increasingly higher scores along this axis as duration of boma occupation increased. The perennial grass C. plectostachyus displayed a strong and significant positive correlation with axis 1 (Fig. 3, Appendix S2: Table S1). A wide variety of perennial and annual grasses, forbs, and subshrubs were negatively correlated with this axis (Fig. 3, Appendix S2: Table S1). As in year 2, NMDS axes 2 and 3 were not strongly associated with boma duration treatments for year 3 data (Fig. 2e, f; Fig. 3). In addition to species identified via the NMDS analysis, we observed that two more Chenopodium species, Datura stramonium, and a Withania species were present in boma sites but entirely absent from control sites during year 2 and/or year 3 .

\section{Plant functional groups and species richness}

Boma duration treatments diverged over time in terms of total plant cover (boma duration $\times$ time $F_{4,93}=4.28$, $P=0.003$ ). Plant cover was similar across boma duration treatments during baseline and five month
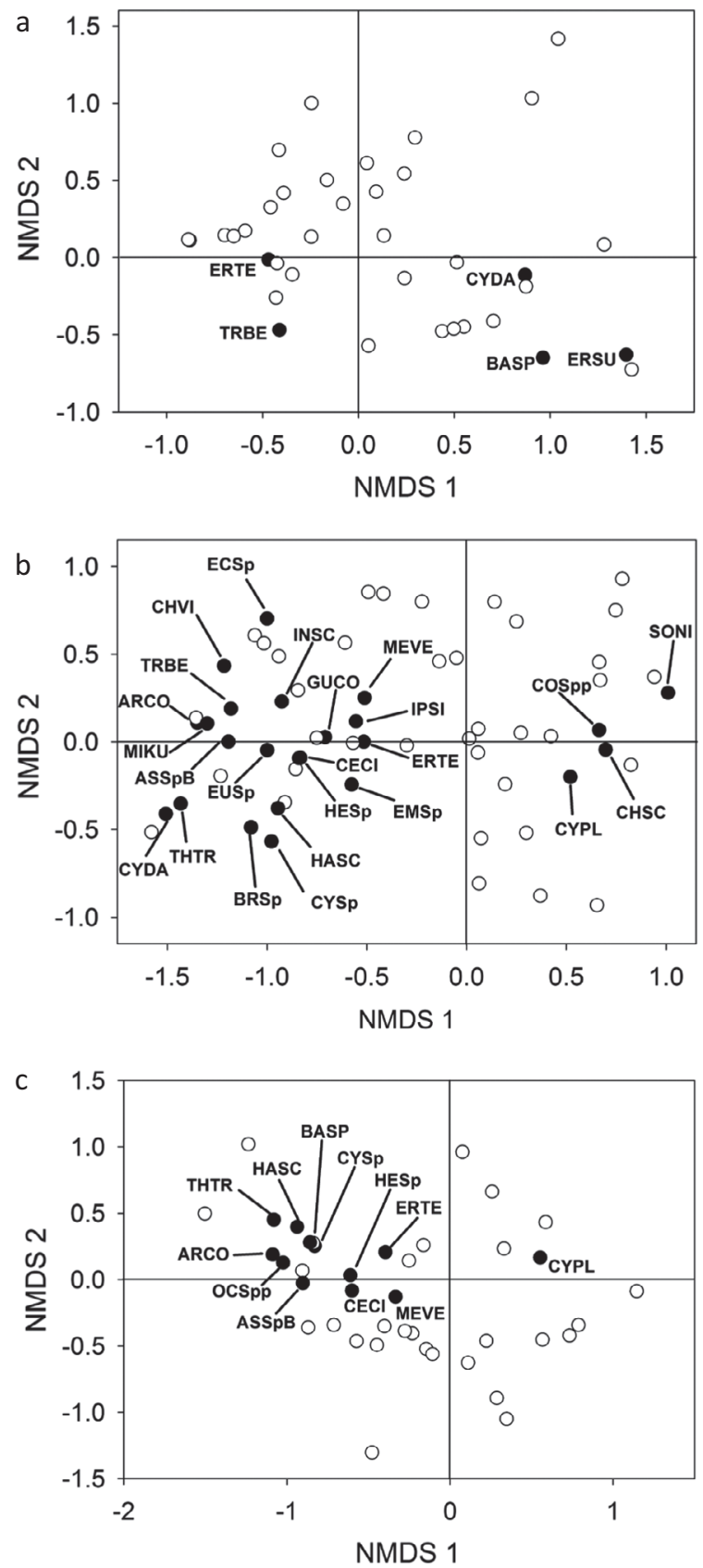

FIG. 3. Plant species scores along NMDS axes 1 and 2 for (a) baseline, (b) $2 \mathrm{yr}$ post-treatment, and (c) $3 \mathrm{yr}$ post-treatment. Species for which relative cover values were significantly correlated with NMDS axis 1 are labeled with four-letter codes and filled circles. Refer to Appendix S2: Table S1 for full species names.

post-treatment survey periods $(P>0.05$; Fig. 4 a) $)$. Cover values then began to diverge at the $1-1.5 \mathrm{yr}$ survey period (Fig. 4a; $F_{4.16}=3.04, \quad P=0.049$, nonsignificant Tukey HSD), when 0-d treatments had approximately one-half as much cover as 7- and 4-d treatments. By theyr 2 sampling period, all four boma treatments had at 
least 2.3 times as much plant cover as the $0-\mathrm{d}$ control sites (Fig. $4 \mathrm{a} ; F_{4,16}=12.05, P=0.0001$ ). This pattern was maintained through the 3 -yr sampling period, at which time all boma treatments had at least 2.75 times as much plant cover as the 0 -d control sites (Fig. $4 \mathrm{a}$; $\left.F_{4,16}=7.92, P=0.001\right)$.

Changes in total plant cover were driven by shifts in graminoid cover (boma duration $\times$ time $F_{4,91}=6.69$, $P<0.0001)$ and, specifically, cover of the glade specialist grass $C$. plectostachyus (boma duration $\times$ time $\left.F_{4,87}=15.8, P<0.0001\right)$. For both parameters, all treatments had similar values during the baseline and 5-month time blocks (Fig. 4b, c; $P>0.10$ ). In the $1-1.5$ yr time block, 4- and 7-d sites had 2.2 times as much

a

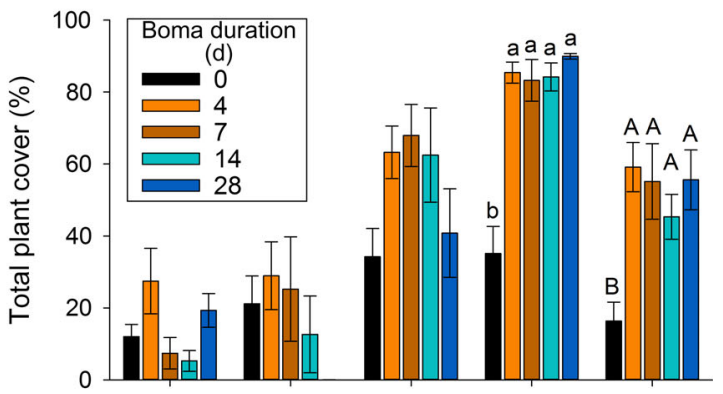

b
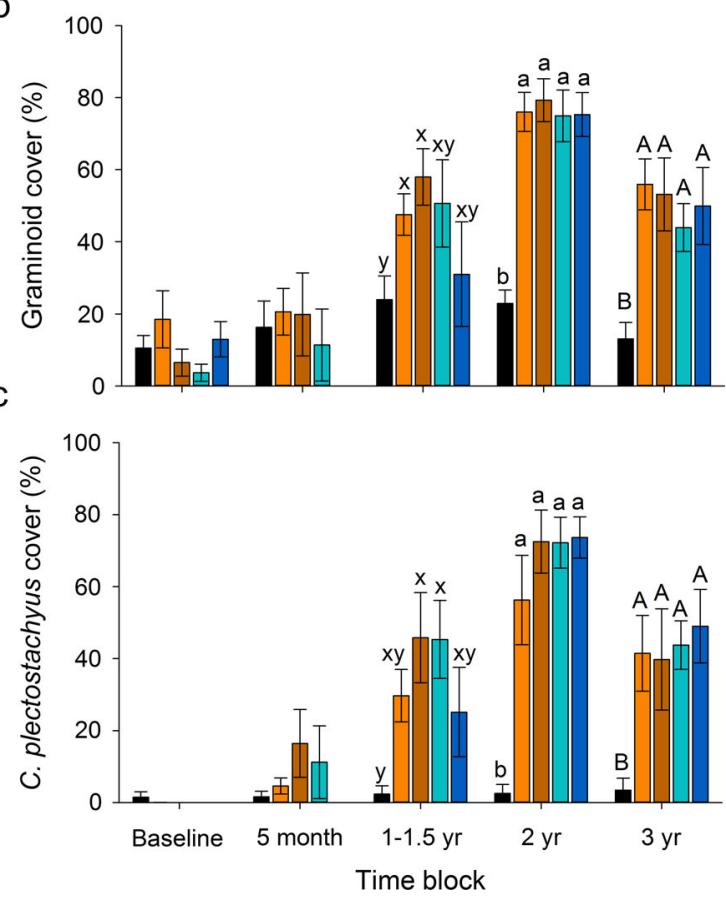

FIG. 4. Effects of boma duration treatments and time since boma abandonment on (a) total plant cover, (b) graminoid cover, and (c) cover of Cynodon plectostachyus. Treatments include 0- (control), 4-, 7-, 14-, and 28-d duration times. For all three response variables, boma duration treatments diverged over time (boma duration $\times$ time $P \leq 0.003$ ). For a given response variable and sampling period (time block), treatments sharing letters do not differ significantly (Tukey HSD). graminoid cover as 0 -d sites (Fig. $3 \mathrm{~b} ; F_{4,16}=4.37$, $P=0.01$ ), and 7- and 14-d sites had 19 times as much $C$. plectostachyus as 0 -d sites (Fig. 4c; $F_{4,16}=5.21$, $P=0.007$ ). During the 2-yr and 3-yr sampling periods, all four boma treatments had at least 3 times as much grass cover and 11 times as much $C$. plectostachyus cover as the control treatment, and there were no significant differences among 4-, 7-, 14- and 28-d boma treatments in terms of grass and C. plectostachyus cover (Fig. 4b, c; grass 2-yr $F_{4,16}=24.6, P<0.0001,3$-yr $F_{4,16}=8.09$, $P=0.0009 ; \quad C . \quad$ plectostachyus $2-\mathrm{yr} \quad F_{4,16}=21.8$, $P<0.0001,3$-yr $\left.F_{4,16}=7.76, P=0.001\right)$. Relative cover data displayed similar patterns; by year 3 , relative cover of $C$. plectostachyus in $0,4,7,14$, and $28 \mathrm{~d}$ boma duration treatments was $19.6 \%, 69.3 \%, 71.2 \%, 95.4 \%$, and $87.8 \%$, respectively.

Cover of perennial grasses other than C. plectostachyus was low across sites and sampling periods. Although only five sites had $>10 \%$ cover of perennial grasses at any sampling time, boma duration treatments did have some influence over cover of these grasses (boma duration $\times$ time $F_{4,84}=3.05, P=0.02$ ). Cover values did not differ during the baseline survey $\left(F_{4,16}=1.62, P=0.2\right.$; Appendix S2: Fig. S2). During the 2-yr sampling period, cover of these grasses was highest at $0-$ and $4-\mathrm{d}$ sites $(6 \%$ and $11 \%$, respectively; $F_{4,16}=5.61, P=0.005$; Appendix S2: Fig. S2). In the third year, 4 -d sites maintained significantly higher cover of these species $(10.6 \%)$ than $14-d$ sites $\left(F_{4,16}=3.32\right.$, $P=0.04$; Appendix S2: Fig. S2).

For cover of short-lived grasses, species richness, bare ground, rock cover, and dung + litter cover, there was an overall effect of boma duration treatment, but the magnitude of this effect did not change significantly over time (boma duration $\times$ time interaction term $P>0.15$ ). Cover of short-lived grasses was four times as high (Fig. 5, Appendix S2: Fig. S3; $F_{4,16}=8.68, P=0.0007$ ) and number of species per $\mathrm{m}^{2}$ was roughly twice as high (Fig. 5, Appendix S2: Fig. S3; $F_{4,21}=7.93, P=0.0005$ ) at 0 - and $4-\mathrm{d}$ sites as at $14-$ and $28-\mathrm{d}$ sites. Forb cover did not differ significantly among boma duration treatments $\left(F_{4,16}=2.00 ; P=0.14\right)$. Control $(0-\mathrm{d})$ sites had more than twice as much bare ground as sites assigned to any boma treatment (Fig. 5, Appendix S2: Fig. S3; $\left.F_{4,32}=17.3, P<0.0001\right)$. Rock cover was also higher at 0 -d sites than at 14-d or 28-d sites (Fig. 4, Appendix S2: Fig. S3; $F_{4,16}=4.87, P=0.009$ ). Conversely, $28-$ and $14-\mathrm{d}$ sites had five times as much dung and litter cover as 0-d sites, while 7- and 4-d sites had intermediate dung and litter cover (Fig. 5, Appendix S2: Fig. S3; $\left.F_{4,15}=11.9, P=0.0001\right)$. To test whether main effects of treatment were due to baseline differences among sites rather than consistent treatment effects following boma abandonment, we ran parallel models on baseline data only. We found that short-lived grass cover, species richness, bare ground, dung + litter, and rock did not differ significantly among treatments during baseline sampling $(P>0.13$; Appendix S2: Fig. S3). 
a

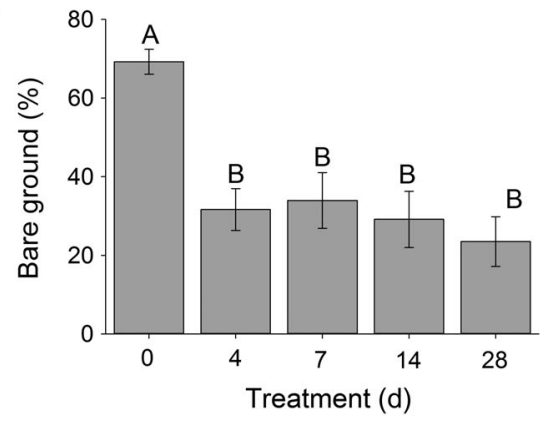

C

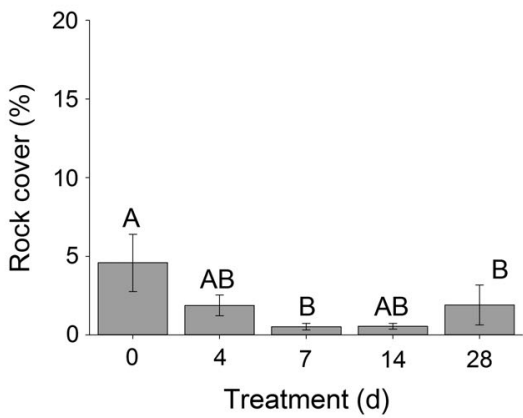

e

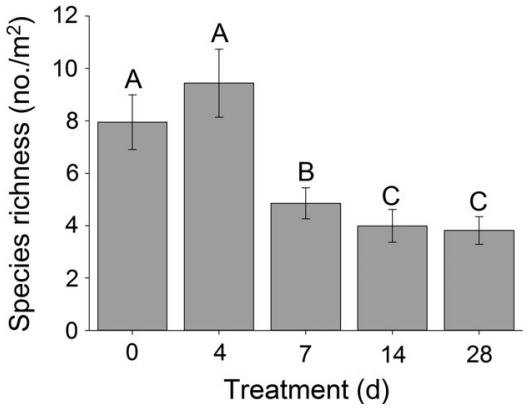

b
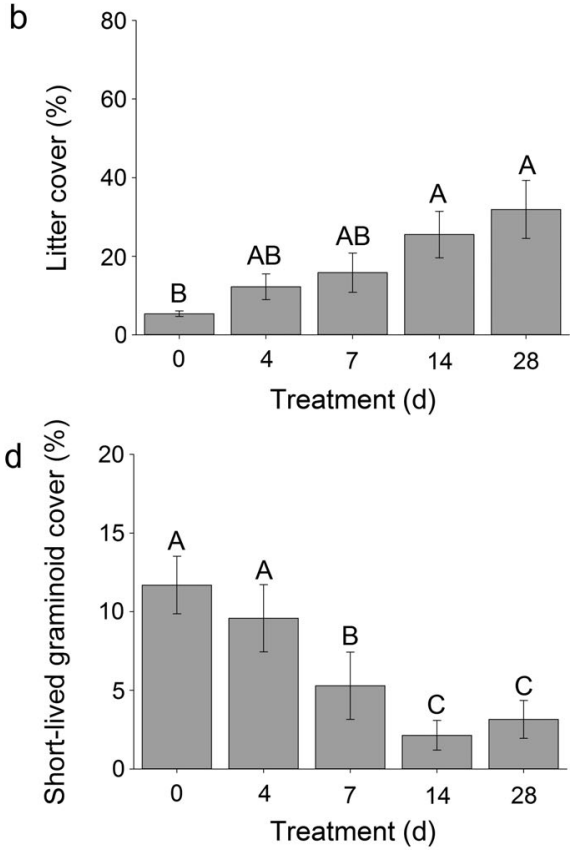

FIG. 5. Effects of boma duration treatments on (a) bare ground, (b) dung and litter, (c) rock, (d) short-lived graminoid cover, and (e) species richness. Treatments include 0- (control), 4-, 7-, 14-, and 28-d duration times. For a given response variable, treatments sharing letters do not differ significantly (Tukey HSD). Data are averaged across sampling periods (for results by sampling period, see Appendix S2: Fig. S3).

\section{Herbivore community change}

For all sample periods, NMDS ordinations on standardized herbivore dung counts required three axes to achieve stress values $<0.15$. For baseline data, blocks and boma duration treatments were not associated with herbivore community structure (Fig. 6a, b, stress $=0.11$, nonmetric fit $R^{2}=0.989$; PerMANOVA Block $F_{4,16}=0.17, P=0.6$; boma duration $F_{4,16}=0.62$, $P=0.9$ ). Axis 1 of the baseline ordination revealed a distinction between communities dominated by elephants and communities dominated by zebra, Grant's gazelle, and impala (Appendix S3: Table S1, Fig. S1). Other axes suggested that certain sites were dominated by giraffe or by hartebeest (Appendix S3: Table S1, Fig. S1).

For the year 1-1.5 sampling period, boma duration treatment and block were not significantly associated with herbivore community composition (Fig. 6c, d, stress $=0.10$, nonmetric fit $R^{2}=0.99$; PerMANOVA boma duration $F_{4,16}=1.42, P=0.16$; block $F_{4,16}=1.22, P=0.3$ ). However, both boma duration treatment and block had significantly influenced herbivore community composition by year 3 (boma duration $F_{4,16}=2.27, \quad P=0.01$; block $\left.F_{4,16}=3.51, P=0.001\right)$. During year 3 , boma duration treatments separated along NMDS axis 1 (Fig. 6e, f, stress $=0.12$, nonmetric fit $R^{2}=0.985$ ). The control treatment was associated with low values along axis 1 , while the 28 -d treatment had high values along this axis, and other treatments had intermediate values. Warthog, Grant's gazelle, dikdik, and impala each displayed significant positive correlations with axis 1 , and elephant and eland also had marginally significant positive correlations (Table 2). In contrast, hares and, to a lesser degree, giraffe were negatively 

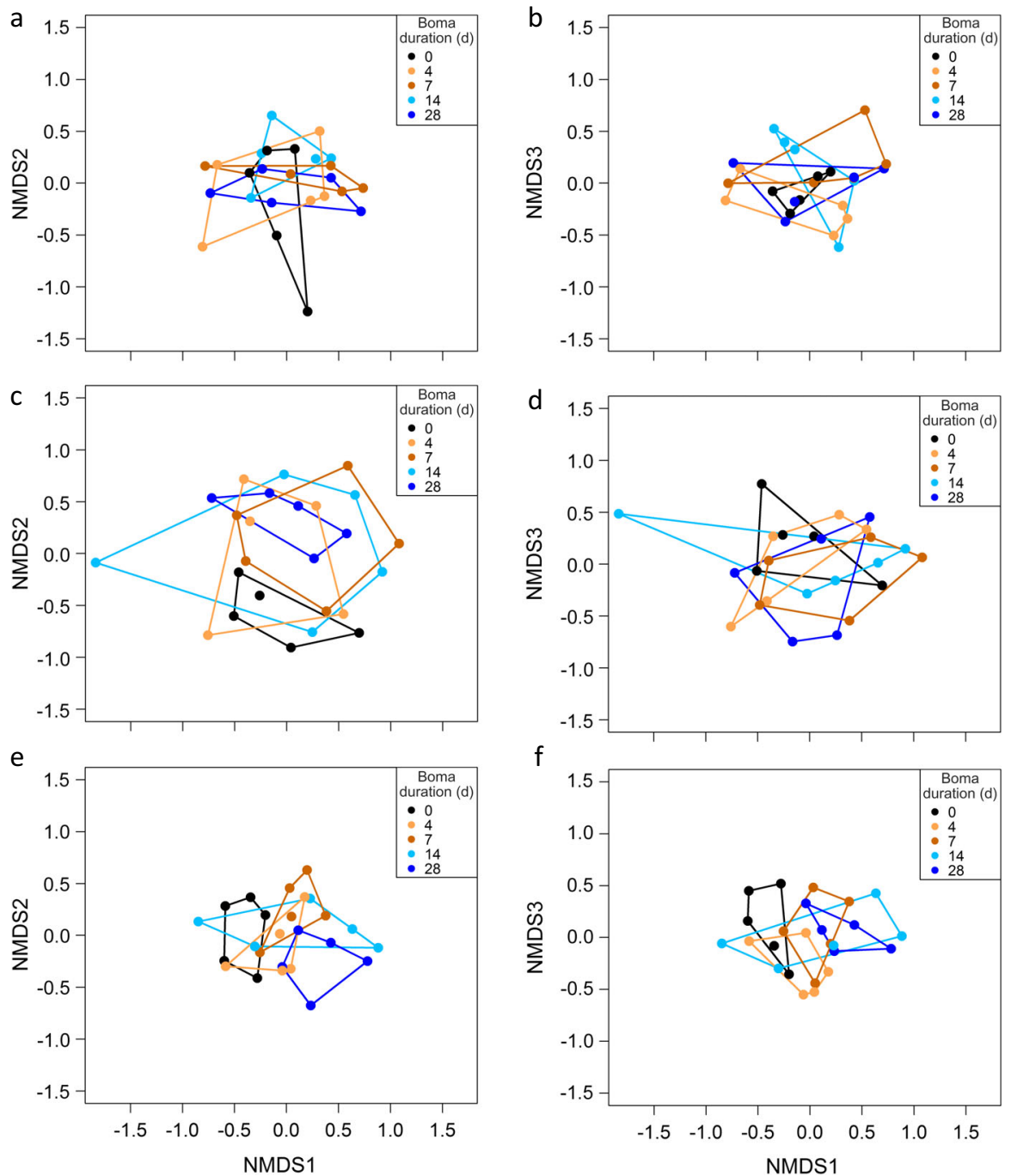

FIG. 6. Nonmetric multidimensional scaling (NMDS) axis scores and convex hulls for herbivore communities (quantified via dung counts) in 0- (control), 4-, 7-, 14-, and 28-d bomas during (a, b) baseline, (c, d) 1-1.5 yr post-treatment, and (e, f) 3 yr posttreatment time periods. See Appendix S3: Fig. S2 for displays of axes 2 vs. 3.

correlated with this axis (Table 2). NMDS axes 2 and 3 were not strongly associated with boma duration treatments for year 3 data (Fig. 6e, f; Appendix S3: Fig. S2).

\section{Herbivore functional groups}

Boma duration treatments diverged over time in their effects on the overall abundance of wild ungulate dung piles (boma duration $\times$ time $F_{4,61}=3.85, P=0.008$; see Appendix S3: Fig. S3). Standardized dung abundance did not differ significantly among treatments during the baseline, 5 month, or 1-1.5 year survey periods $(P>0.06)$. However, during the 3 -yr sampling period, $14-$ and 28-d sites had almost seven times as many wild ungulate dung piles as 0 -d sites (Fig. 7; $F_{4,16}=5.32$,
TABLE 2. Significant and marginally significant correlations between standardized dung densities for individual herbivore species and NMDS axis 1, which was associated with boma duration treatments, in year 3 .

\begin{tabular}{lcc}
\hline \hline Species & Correlation & $P$ \\
\hline Hares (Lepus spp.) & -0.48 & 0.0149 \\
Giraffe (Giraffa camelopardalis) & -0.38 & 0.0586 \\
Elephant (Loxodonta africana) & 0.35 & 0.0883 \\
Eland (Taurotragus oryx) & 0.39 & 0.0567 \\
Impala (Aepyceros melampus) & 0.47 & 0.0180 \\
Dikdik (Madoqua guentheri) & 0.52 & 0.0079 \\
Grant's gazelle (Gazella grantii) & 0.66 & 0.0003 \\
Warthog (Phacochoerus africanus) & 0.69 & 0.0001
\end{tabular}

Note: See Appendix $\mathrm{S} 3$ for additional correlations between species and NMDS axes, as well as NMDS species scores. 
$P=0.006$ ). Although the larger sampling area in year 3 may have improved precision of dung results in that year, the similarly sized errors associated with means across all sample periods, along with the large magnitude of differences among treatments in year 3 , are consistent

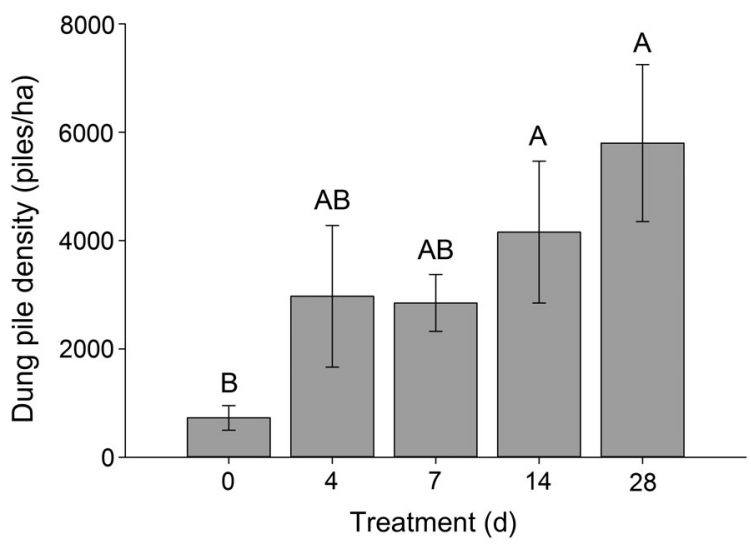

FIG. 7. Effects of boma duration treatments on the density of dung piles for wild ungulates $3 \mathrm{yr}$ after boma abandonment. Treatments include 0- (control), 4-, 7-, 14-, and 28-d duration times. Boma duration treatments diverged over time (boma duration $\times$ time $P=0.008)$. Treatments sharing letters do not differ significantly (Tukey HSD). Values shown are raw densities but analyses were performed on standardized densities. with our interpretation that wild herbivore preference for 14- and 28-d bomas did not fully manifest until year 3. Standardized dung abundances did not differ significantly across boma duration treatments for livestock or hares (boma duration and boma duration $x$ time $P>0.05)$.

\section{Discussion}

Globally, managing for tipping points or thresholds between alternative states has been and will continue to be of central importance, particularly as issues such as climate change and invasive species become more problematic in the future. In rangelands, a great deal of work has gone into understanding transitions among alternative states and how to meaningfully apply this knowledge to land management (Briske et al. 2005, Kachergis et al. 2011, Bestelmeyer et al. 2017, Tipton et al. 2018). However, the idea that different ecosystem components may provide incomplete or inaccurate information about state changes has rarely been addressed in the literature. Here, we have shown that measurement of more than one ecosystem attribute can lead to different conclusions about the threshold of disturbance required to create cattle corral-derived "ecosystem hotspots" (Fig. 8). Although plant communities in our study responded to relatively low intensities of disturbance, herbivore a)

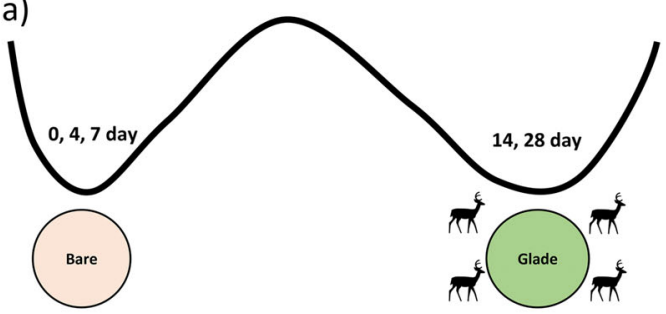

b)

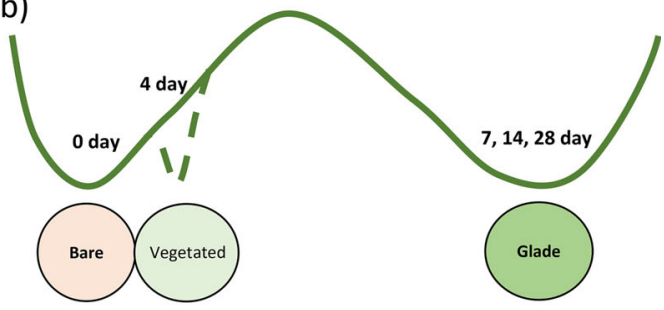

d)

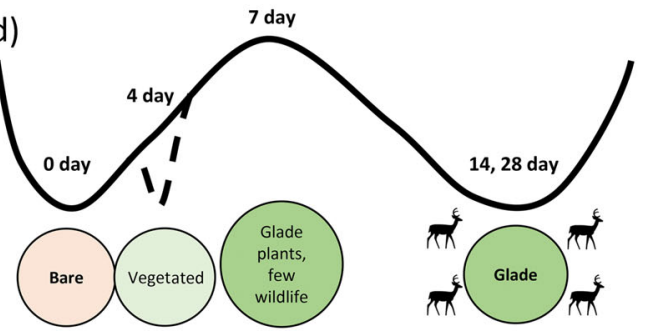

c)

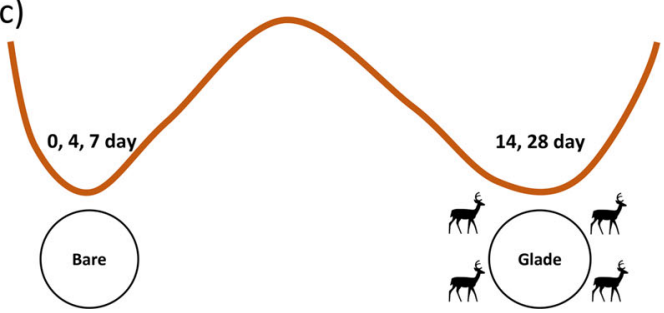

FIG. 8. Implications of multiple response variables on threshold conceptualizations for a system in which we tested how different lengths of occupation time control the conversion of cattle corrals ("bomas") into "glades" that are dominated by the grass, Cynodon plectostachyus (CYPL) and preferred by wild herbivores. (a) Our initial hypothesis for this system was that there were two stable states separated by a threshold: a "bare" unvegetated state that does not attract wild herbivores and a "glade" state dominated by CYPL and preferred by wild herbivores. (b) Based on vegetation results alone, we would have concluded that the threshold is located between our 4- and 7-d treatments. The 7-, 14-, and 28-d bomas were dominated by CYPL, whereas the 4-d treatment was vegetated, but retained non-CYPL species. The 4-d boma may represent a transient or stable state (the latter indicated by the dotted line). (c) Based on wild herbivore results alone, we would have concluded that the threshold is located between our 7- and 14-d treatments because the 14- and 28-d bomas were preferentially used by wild herbivores. (d) Measurement of multiple ecosystem components led to a better understanding of potentially transient or unstable phases occurring within our conceptual framework. For example, both 4- and 7-d treatments may not receive enough wild herbivore use to create the plant-herbivore feedbacks necessary to cross an ecosystem-level threshold into a stable "glade" state. 
communities only responded to higher disturbance intensities. That the herbivore response was either lagged or lacking altogether for lower disturbance intensities has potential functional consequences for the plant-herbivore feedbacks that maintain these hotspots over the long term.

\section{Vegetation response}

Disturbance often can lead to establishment of lowdiversity plant communities (Hobbs and Huenneke 1992), and we indeed found that more heavily disturbed boma sites were colonized by lower diversity plant communities of disturbance-adapted species. Significant increases in grass cover occurred sooner on shorteroccupied than longer-duration sites (i.e., after 1-1.5 yr in 4- and 7-d treatments vs. after $2 \mathrm{yr}$ in 14- and 28-d treatments), likely because the more moderate levels of dung accumulation in shorter-occupied bomas were more hospitable to plant establishment. Within 1-2 yr, the 7-, 14-, and 28-d boma duration treatments in our experiment appeared to have undergone a complete transition to plant communities characteristic of glade hotspots that develop on the sites of traditional longterm bomas. By $3 \mathrm{yr}$ post-treatment, bomas in these treatments were dominated by Cynodon plectostachyus, a member of a genus that dominates glades in our region (Young et al. 1995, Augustine 2003b, Veblen 2012, Porensky and Veblen 2015) and elsewhere in eastern and southern Africa (Treydte et al. 2006, Muchiru et al. 2009). The clear plant community level distinctions among boma duration treatments at this time were tightly linked to high C. plectostachyus cover in 7-, 14-, and 28-d boma treatments coupled with low cover of other grass species. Additionally, although forbs as a functional group did not respond significantly to boma duration treatments, boma treatments appeared to increase some key, boma-associated forb species and reduce others. Forbs significantly associated with boma sites in year 2 included Solanum nigrum, Chenopodium schraderianum, and Commelina spp. (Appendix S2: Table S1). We also observed that two additional Chenopodium species, Datura stramonium, and a Withania species were present in boma sites but entirely absent from control sites during years 2 and/or 3 .

Our data show that the shortest boma duration treatment (4-d) did not completely convert to a glade plant community by year 3 . Although the vegetation communities at 4-d experimental sites were still dominated by the glade-associated grass C. plectostachyus, they simultaneously supported relatively high cover of non-glade plant species. This is in contrast to long-term glade sites in our study system (Young et al. 1995, Augustine 2003b, Veblen 2012) and elsewhere (Treydte et al. 2006, Muchiru et al. 2009, Sibanda et al. 2016) that are characterized by low overall plant diversity. We found that losses in species richness in our longer-term boma duration treatments likely came in the form of reduced abundances of short-lived and other perennial grasses. That the 4-d bomas had the highest cover of these grasses and twice the species richness of the longest boma duration treatments suggests that the minimum boma duration required to develop glade plant communities may be between 4 and $7 \mathrm{~d}$ in this ecosystem. Our results align with those of Huruba et al. 2018, who showed $7 \mathrm{~d}$ to be sufficient to create glade-like vegetation at a site in southern Africa. In contrast, Sibanda et al. (2016) suggested that $7 \mathrm{~d}$ was insufficient to initiate conversion to glade-like plant composition in a Zimbabwean savanna. To our knowledge, we are the first to directly test several different durations of occupation in the same system and identify a minimum duration required to initiate vegetation conversion.

Given their higher species richness, it remains unclear whether the shortest duration (4-d) boma sites will continue on a trajectory toward complete conversion to glade vegetation and virtual monoculture of $C$. plectostachyus, or will instead maintain higher species richness or even revert to a non-glade state (Fig. 8d). It is possible that these short duration bomas will indeed cross a threshold of vegetation composition and wildlife use, but that it will simply take a longer time following boma abandonment to create self-sustaining hotspots. Alternatively, plant communities at these sites may ultimately fail to cross a threshold and instead revert to non-glade vegetation composition (Fig. 8d). Failure to cross the glade threshold would likely be caused by insufficient livestock dung deposition during boma use, which could lead to baseline nutrient levels that are too low to facilitate conversion to glade vegetation. Additionally, if shorter-duration (i.e., both 4- and 7-d) sites fail to attract wild herbivores due to non-preferred plant species composition or lower forage quality, nutrient levels may gradually decline due to insufficient deposition of the nutrient-rich wild herbivore dung that helps maintain glade-specialist vegetation in established glades. Regardless of their eventual fate, these 4-d boma sites produced plant communities that do not resemble the original bare ground-dominated state, but also do not completely resemble the glade state.

\section{Herbivore response}

In our experiment, all boma duration treatments $>4 \mathrm{~d}$ suggested a state change in terms of vegetation composition, but wildlife communities only changed significantly in the longest duration (14- and 28-d) treatments. In year 3 , dung abundance of wild herbivore species increased with increasing boma duration. Herbivore community changes associated with boma duration were driven by higher abundances of Grant's gazelle, dikdik, impala, and warthog. Except for warthog, these species are smaller-bodied browsing and mixed feeding herbivores that seek out higher quality forage (Demment and Van Soest 1985). Larger animals like eland and elephants that feed on forbs in this study system (Young et al. 2005) also 
showed marginally significant associations with boma duration. All of these wildlife species may have been tracking nutrient availability (e.g., Anderson et al. 2010, Merkle et al. 2016) and the high forage quality associated with glades (Augustine 2004, Chikorowondo et al. 2017, Huruba et al. 2017).

Our results show that 4-d bomas were not characterized by glade-like plant species composition or glade-like wildlife attraction. In contrast, 7-d bomas were characterized by glade-like plant communities, but did not attract wild herbivores. These 7-d site results emphasize that wildlife foraging decisions are shaped not only by plant species composition, but by other factors as well. Though we were unable to collect data on forage quality during this experiment, we hypothesize that higher forage quality on abandoned boma sites (van der Waal et al. 2011, Sibanda et al. 2016, Huruba et al. 2018), and presumably higher forage quality on the longeroccupied boma sites, is one such important factor (sensu Augustine 2004).

Even in the longest boma duration treatments (14and 28-d sites), wildlife responses took longer to appear than did plant community change; divergence in overall herbivore community structure among boma duration times was not apparent until year 3 despite plant community conversions occurring $1-1.5 \mathrm{yr}$ after boma treatments were established. Time-lagged wildlife responses may indicate that wild herbivores are not attracted to abandoned boma sites until after the initial phases of vegetation community conversion take place.

Several other herbivores showed negative or neutral responses to boma treatments in year 3. Dung abundance levels for hares and giraffes were negatively related to boma duration; these species were most abundant at control sites, which continued to be dominated by bare ground (which may be attractive to hares for predator detection) and woody plants (which constitute the primary forage for giraffes). Zebras, which are the most abundant grazing wildlife species $(6-10 \times$ the dung densities of other grazers), did not respond to boma duration, likely because they are large, hind-gut fermenters that would not be expected to seek out high-quality forage on glades. Only longer-term monitoring will reveal whether this pattern persists or if grazing wildlife shows a more time-lagged response to boma treatments, e.g., if productivity increases over time due to feedbacks with browsing and mixed feeding herbivores. Cattle, which are herded by humans, also showed no preference for bomas; it may be that they were moved out of our study area temporarily but could return in the future.

\section{Reconciling response variables}

For non-vegetation attributes such as ecosystem functions and wildlife use, thresholds and tipping points remain poorly understood (Bestelmeyer et al. 2017). Our results show that conclusions about the point at which a boma crosses a threshold into a glade hotspot may depend on the ecosystem attribute being measured (Fig. 8b, c). For plant communities, even the shortest, 4$\mathrm{d}$, bomas resembled glades in many ways after $1-1.5 \mathrm{yr}$, and bomas used for $>4 \mathrm{~d}$ appeared to undergo a complete conversion to glade-like plant communities (Fig. 8b). In contrast, only the longest duration, 14- and 28-d, bomas attracted significantly more wild herbivores than 0 -d sites, and this attraction was only apparent after 3 yr (Fig. 8c).

Despite ample literature on feedbacks among ecosystem components such as herbivores, plants, and soils (e.g., Hobbs 1996) little work has explored how such feedbacks may shape or influence ecosystem thresholds. In the simplest case, as we observed for wild herbivores, animal responses might be lagged if plant community shifts are required in order to precipitate changes in animal distribution or use. It is also possible, however, that specific plant-herbivore interactions or feedbacks are necessary to precipitate an ecosystem-scale transition or maintain an alternative state. For example, if shorteroccupied boma sites do not attract wildlife sufficient to create feedbacks that maintain elevated nutrient levels (sensu Augustine 2003a, Veblen and Young 2010, Porensky and Veblen 2012, Veblen 2012), they may revert to non-glade vegetation. Our results support the hypothesis that the disturbance intensity necessary to initiate such plant-herbivore feedbacks may differ from that necessary to initiate vegetation change. This incongruity is likely of functional significance. Previous research suggests that to achieve full, long-term functionality as glades, our experimental treatments would have to cross thresholds for both the plant and animal variables we investigated, as well as other variables we did not assess in the present study such as soil nutrient levels (sensu Augustine 2003a, Veblen 2012, Chikorowondo et al. 2017), invertebrate communities (sensu Donihue et al. 2013), or predator habitat use patterns (Van Cleave et al. 2018). Therefore, we hypothesize that after $3 \mathrm{yr}$, the 4and 7-d sites existed in unstable or transient states (Fig. 8d). Future assessments will enable us to determine how discrepancies between plant and herbivore responses influence long-term outcomes for these experimental glade sites.

\section{Management implications}

Here, we have experimentally tested how the intensity of disturbance associated with short-term cattle corrals (i.e., duration of boma occupation) can be manipulated to create desirable "ecosystem hotspots." For managers wishing to use short-term mobile bomas to reduce bare ground, even the shortest duration boma treatments (which had double the plant cover of untreated sites by $1-1.5 \mathrm{yr}$ following treatment) appear to be a viable restoration tool. The reductions in bare ground we observed have the benefit of mitigating undesirable processes such as erosion and overland sheet flow of water (Gutierrez and Hernandez 1996, Kimiti et al. 2017), and 
the increased litter and dung at these sites provide benefits such as increasing organic matter and nutrient cycling (Scholes 1990, Augustine 2003a, Porensky and Veblen 2015). Use of the 4-d treatment represents a potential tradeoff between maintaining higher local plant species diversity (but similar total plant cover) compared to longer duration treatments vs. potentially failing to attract wildlife and persist in a glade-like state over the long term.

Although the effectiveness of short-term mobile boma treatments for increasing ground cover is attractive because these bomas could be used to cover a high proportion of the landscape, caution is warranted for three main reasons. First, high densities of low diversity, short-structure vegetation communities associated with 7- and 14-d boma sites would lower plant and habitat diversity at the landscape scale. Second, as discussed above, shorter duration treatments may be insufficient to create the feedbacks with wild herbivores that are necessary to maintain functional glades over the long term (but may nonetheless reduce plant diversity). Third, impacts of short-duration bomas on other glade functions still need to be tested; for example, because nutrient enrichment of bomas sites entails redistribution (rather than addition) of nutrients across landscape, high densities of shorter-duration bomas could lead to reduced nutrient status of individual glade sites (see Porensky and Veblen 2015). Overall, our results clarify that managers can expect different outcomes from different boma durations, and certain durations may be more or less appropriate for different management objectives. For example, if the objective is simply to reduce bare ground cover, 4-d boma sites may accomplish that objective relatively quickly and with minimal loss of plant diversity. If the goal is to create long-term ecosystem hotspots, durations of use $>7 \mathrm{~d}$ will be necessary.

\section{Conclusions}

We contend that a major current challenge is to understand threshold dynamics associated not only with vegetation responses (as has been a central, productive focus of the literature on rangeland state-and-transition models), but with a broader suite of response variables that together provide a more complete representation of ecosystem function. In practice, this means assessment of multiple response variables (and potential feedbacks among them) and contending with the possibility that they may respond differently from one another. Here, we have shown that two variables of interest, plant and animal communities, when considered independently, provide two different conclusions about the timescales and disturbance levels beyond which bare ground areas transition to resemble corral-derived ecosystem hotspots. As state-and-transition models are broadened to include more details about animal use and ecosystem function, descriptions of transitions may need to include more nuance related to time-lagged responses or the initiation of required feedbacks among multiple response variables. Unraveling these types of complexity will challenge managers to optimize among multiple variables but also provide opportunities for more successful ecosystem management.

\section{AcKNowledgments}

We thank Frederick Erii, John Lochukuya, Mathew Namoni, and Jackson Ekadeli for their invaluable assistance in the field. We also thank Mike Littlewood and the Mpala Conservancy staff for their logistical support. This research was supported in part by The National Science Foundation (08-16453, 12-56004, and 12-56034), the Utah Agricultural Experiment Station, and the USDA Agricultural Research Service. This research complies with Kenyan law and was approved by the Kenyan Ministry of Science and Technology.

\section{Literature Cited}

Ahn, P. M., and L. C. Geiger. 1987. Kenya Soil Survey-Soils of Laikipia District. Ministry of Agriculture, National Agricultural Laboratories, Kabete, Kenya.

Alday, J. G., E. S. Cox, R. J. Pakeman, M. P. K. Harris, M. G. Le Duc, and R. H. Marrs. 2013. Overcoming resistance and resilience of an invaded community is necessary for effective restoration: a multi-site bracken control study. Journal of Applied Ecology 50:156-167.

Anderson, T. M., J. G. C. Hopcraft, S. Eby, M. Ritchie, J. B. Grace, and H. Olff. 2010. Landscape-scale analyses suggest both nutrient and antipredator advantages to Serengeti herbivore hotspots. Ecology 91:1519-1529.

Augustine, D. J. 2003a. Long-term, livestock-mediated redistribution of nitrogen and phosphorus in an East African savanna. Journal of Applied Ecology 40:137-149.

Augustine, D. J. 2003b. Spatial heterogeneity in the herbaceous layer of a semi-arid savanna ecosystem. Plant Ecology 167:319-322.

Augustine, D. J. 2004. Influence of cattle management on habitat selection by impala on central Kenyan rangeland. Journal of Wildlife Management 68:916-923.

Augustine, D. J., J. D. Derner, and J. K. Detling. 2014. Testing for thresholds in a semiarid grassland: the influence of prairie dogs and plague. Rangeland Ecology and Management 67:701-709.

Bagchi, S., D. D. Briske, B. T. Bestelmeyer, and X. Ben Wu. 2013. Assessing resilience and state-transition models with historical records of cheatgrass Bromus tectorum invasion in North American sagebrush-steppe. Journal of Applied Ecology 50:1131-1141.

Barnes, R. F. W. 2001. How reliable are dung counts for estimating elephant numbers? African Journal of Ecology 39:1-9.

Bestelmeyer, B. T., M. C. Duniway, D. K. James, L. M. Burkett, and K. M. Havstad. 2013. A test of critical thresholds and their indicators in a desertification-prone ecosystem: more resilience than we thought. Ecology Letters 16:339-345.

Bestelmeyer, B. T., et al. 2017. State and transition models: theory, applications, and challenges. Pages $303-345$ in D. D. Briske, editor. Rangeland systems: processes, management and challenges. Springer International Publishing, Cham, Switzerland.

Blackmore, A. C., M. T. Mentis, and R. J. Scholes. 1990. The origin and extent of nutrient-enriched patches within a nutrient-poor savanna in South-Africa. Journal of Biogeography 17:463-470. 
Briske, D. D., S. D. Fuhlendorf, and F. E. Smeins. 2003. Vegetation dynamics on rangelands: a critique of the current paradigms. Journal of Applied Ecology 40:601-614.

Briske, D. D., S. D. Fuhlendorf, and F. E. Smeins. 2005. Stateand-transition models, thresholds, and rangeland health: a synthesis of ecological concepts and perspectives. Rangeland Ecology and Management 58:1-10.

Bruegger, R. A., M. E. Fernandez-Gimenez, C. Y. Tipton, J. M. Timmer, and C. L. Aldridge. 2016. Multistakeholder development of state-and-transition models: a case study from northwestern Colorado. Rangelands 38:336-341.

Chikorowondo, G., J. Muvengwi, M. Mbiba, and E. Gandiwa. 2017. Influence of abandoned cattle enclosures on plant assemblages and herbivory in a semi-arid savanna. Ecological Research 32:1023-1033.

Courtois, D. R., B. L. Perryman, and H. S. Hussein. 2004. Vegetation change after 65 years of grazing and grazing exclusion. Journal of Range Management 57:574-582.

Demment, M. W., and P. J. Van Soest. 1985. A nutritional explanation for body size patterns of ruminant and nonruminant herbivores. American Naturalist 125:641-672.

Donihue, C. M., L. M. Porensky, J. Foufopoulus, C. Riginos, and R. M. Pringle. 2013. Glade cascades: indirect legacy effects of pastoralism enhance the abundance and spatial structuring of arboreal fauna. Ecology 94:827-837.

Ellsworth, L. M., D. W. Wrobleski, J. B. Kauffman, and S. A. Reis. 2016. Ecosystem resilience is evident 17 years after fire in Wyoming big sagebrush ecosystems. Ecosphere 7:e01618.

Ford, A. T., J. R. Goheen, T. O. Otieno, L. Bidner, L. A. Isbell, T. M. Palmer, D. Ward, R. Woodroffe, and R. M. Pringle. 2014. Large carnivores make savanna tree communities less thorny. Science 346:346.

Fuhlendorf, S. D., D. D. Briske, and F. E. Smeins. 2001. Herbaceous vegetation change in variable rangeland environments: the relative contribution of grazing and climatic variability. Applied Vegetation Science 4:177-188.

Gutierrez, J., and I. I. Hernandez. 1996. Runoff and interrill erosion as affected by grass cover in a semi-arid rangeland of northern Mexico. Journal of Arid Environments 34:287-295.

Harrison, S., E. I. Damschen, and J. B. Grace. 2010. Ecological contingency in the effects of climatic warming on forest herb communities. Proceedings of the National Academy of Sciences USA 107:19362-19367.

Hobbs, N. T. 1996. Modification of ecosystems by ungulates. Journal of Wildlife Management 60:695-713.

Hobbs, R. J., and L. F. Huenneke. 1992. Disturbance, diversity, and invasion: implications for conservation. Conservation Biology 6:324-337.

Huruba, R., P. J. Mundy, A. Sebata, G. K. Purchase, and D. N. MacFadyen. 2017. Impala, Aepyceros melampus: Does browse quality influence their use of sites originally utilised as short-duration kraals in a southern African savanna? Rangeland Journal 39:113

Huruba, R., T. Mlambo, P. J. Mundy, A. Sebata, and D. N. MacFadyen. 2018. Short duration overnight cattle kraaling in natural rangelands: implications for grass composition, quality, above ground biomass, species diversity and basal cover. Agriculture, Ecosystems \& Environment 257:144-151.

Kachergis, E., M. E. Rocca, and M. E. Fernandez-Gimenez. 2011. Indicators of ecosystem function identify alternate states in the sagebrush steppe. Ecological Applications 21:2781-2792.

Kachergis, E., M. E. Rocca, and M. E. Fernández-Giménez. 2014. Long-term vegetation change provides evidence for alternate states in silver sagebrush. Rangeland Ecology \& Management 67:183-194.
Kimiti, D. W., C. Riginos, and J. Belnap. 2017. Low-cost grass restoration using erosion barriers in a degraded African rangeland. Restoration Ecology 25:376-384.

Marshall, F., R. E. B. Reid, S. Goldstein, M. Storozum, A. Wreschnig, L. Hu, P. Kiura, R. Shahack-Gross, and S. H. Ambrose. 2018. Ancient herders enriched and restructured African grasslands. Nature 561:387-390.

Merkle, J. W., K. L. Monteith, E. O. Aikens, M. M. Hayes, K. R. Hersey, A. D. MIddelton, B. A. Oates, H. Sawyer, B. M. Scurlock, and M. J. Kauffman. 2016. Large herbivores surf waves of green-up during spring. Proceedings of the Royal Society B 283:20160456.

Miller, M. E., R. T. Belote, M. A. Bowker, and S. L. Garman. 2011. Alternative states of a semiarid grassland ecosystem: implications for ecosystem services. Ecosphere 2:1-18.

Milton, S. J., and M. T. Hoffman. 1994. The application of state-and-transition models to rangeland research and management in arid succulent and semi-arid grassy Karoo, South Africa. African Journal of Range and Forage Science 11:18 26.

Muchiru, A. N., D. Western, and R. S. Reid. 2009. The impact of abandoned pastoral settlements on plant and nutrient succession in an African savanna ecosystem. Journal of Arid Environments 73:322-331.

Ng'weno, C. C., S. W. Buskirk, N. J. Georgiadis, B. C. Gituku, A. K. Kibungei, L. M. Porensky, D. I. Rubenstein, and J. R. Goheen. 2019. Apparent Competition, Lion Predation, and Managed Livestock Grazing: Can Conservation Value Be Enhanced? Frontiers in Ecology and Evolution 7:123.

Oksanen, J., F. Guillaume Blanchet, M. Friendly, R. Kindt, P. Legendre, D. McGlinn, P. R. Minchin, R. B. O'Hara, G. L. Simpson, P. Solymos, M. H. M. Stevens, E. Szoecs, and H. Wagner. 2018. vegan: Community Ecology Package. R package version 2.5-1. https://CRAN.R-project.org/package=vegan.

Otieno, T. O., J. R. Goheen, P. W. Webala, A. Mwangi, I. M. Osuga, and A. T. Ford. 2019. Human- and risk-mediated browsing pressure by sympatric antelope in an African savanna. Biological Conservation 232:59-65.

Porensky, L. M. 2011. When edges meet: interacting edge effects in an African savanna. Journal of Ecology 99:923-934.

Porensky, L. M., and K. E. Veblen. 2012. Grasses and browsers reinforce landscape heterogeneity by excluding trees from ecosystem hotspots. Oecologia 168:749-759.

Porensky, L. M., and K. E. Veblen. 2015. Generation of ecosystem hotspots using short-term cattle corrals in an African savanna. Rangeland Ecology and Management 68:131-141.

Porensky, L. M., K. E. Mueller, D. J. Augustine, and J. D. Derner. 2016. Thresholds and gradients in a semi-arid grassland: long-term grazing treatments induce slow, continuous and reversible vegetation change. Journal of Applied Ecology 53:1013-1022.

Porensky, L. M., J. D. Derner, and D. W. Pellatz. 2018. Plant community responses to historical wildfire in a shrublandgrassland ecotone reveal hybrid disturbance response. Ecosphere 9:e02363.

R Core Team. 2016. R: A language and environment for statistical computing. R Foundation for Statistical Computing, Vienna, Austria. URL http://www.R-project.org/.

Ratajczak, Z., J. B. Nippert, J. M. Briggs, and J. M. Blair. 2014. Fire dynamics distinguish grasslands, shrublands and woodlands as alternative attractors in the Central Great Plains of North America. Journal of Ecology 102:1374-1385.

Reid, R. S., and J. E. Ellis. 1995. Impacts of pastoralists on woodlands in south Turkana, Kenya - livestock-mediated tree recruitment. Ecological Applications 5:978-992. 
Riginos, C. 2015. Climate and the landscape of fear in an African savanna. Journal of Animal Ecology 84:124-133.

Riginos, C., and J. B. Grace. 2008. Savanna tree density, herbivores, and the herbaceous community: bottom-up versus topdown effects. Ecology 89:2228-2238.

Sasaki, T., T. Okayasu, U. Jamsran, and K. Takeuchi. 2008. Threshold changes in vegetation along a grazing gradient in Mongolian rangelands. Journal of Ecology 96:145-154.

Scheffer, M. 2009. Critical transitions in nature and society. Princeton University Press, Princeton, New Jersey, USA.

Scholes, R. J. 1990. The influence of soil fertility on the ecology of southern African dry savannas. Journal of Biogeography 17:415-419.

Sibanda, P., A. Sebata, E. Mufandaedza, and M. Mawanza. 2016. Effect of short-duration overnight cattle kraaling on grass production in a southern African savanna. African Journal of Range and Forage Science 33:217-223.

Stelfox, J. B. 1986. Effects of livestock enclosures (bomas) on the vegetation of the Athi Plains, Kenya. African Journal of Ecology 24:41-45.

Stringham, T. K., W. C. Krueger, and P. L. Shaver. 2003. State and transition modeling: an ecological process approach. Journal of Range Management 56:106-113.

Taiti, S. W. 1992. The vegetation of Laikipia District, Kenya. Laikipia-Mount Kenya Papers, B-2. Laikipia Research Programme, Universities of Nairobi and Berne, Bern, Switzerland.

Tipton, C. Y., T. W. Ocheltree, K. E. Mueller, P. Turk, and M. E. Fernández-Giménez. 2018. Revision of a state-and-transition model to include descriptions of state functional attributes. Ecosphere 9:e02201.

Treydte, A. C., S. M. Bernasconi, M. Kreuzer, and P. J. Edwards. 2006. Diet of the common warthog (Phacochoerus africanus) on former cattle grounds in a Tanzanian savanna. Journal of Mammalogy 87:889-898.

Twidwell, D., S. D. Fuhlendorf, C. A. Taylor, and W. E. Rogers. 2013. Refining thresholds in coupled fire-vegetation models to improve management of encroaching woody plants in grasslands. Journal of Applied Ecology 50:603-613.

Valone, T. J., M. Meyer, J. H. Brown, and R. M. Chew. 2002. Timescale of perennial grass recovery in desertified arid grasslands following livestock removal. Conservation Biology 16:995-1002.
Van Cleave, E. K., L. R. Bidner, A. T. Ford, D. Caillaud, C. C. Wilmers, and L. A. Isbell. 2018. Diel patterns of movement activity and habitat use by leopards (Panthera pardus pardus) living in a human-dominated landscape in central Kenya. Biological Conservation 226:224-237.

van de Koppel, J., M. Rietkerk, and F. J. Weissing. 1997. Catastrophic vegetation shifts and soil degradation in terrestrial grazing systems. Trends in Ecology and Evolution 12:352-356.

van der Waal, C., et al. 2011. Large herbivores may alter vegetation structure of semi-arid savannas through soil nutrient mediation. Oecologia 165:1095-1107.

Veblen, K. E. 2012. Savanna glade hotspots: plant community development and synergy with large herbivores. Journal of Arid Environments 78:119-127.

Veblen, K. E., and T. P. Young. 2010. Contrasting effects of cattle and wildlife on the vegetation development of a savanna landscape mosaic. Journal of Ecology 98:993-1001.

Westoby, M., B. Walker, and I. Noy-Meir. 1989. Opportunistic management for rangelands not at equilibrium. Journal of Range Management 42:266-274.

Young, T. P., N. Patridge, and A. Macrae. 1995. Long-term glades in acacia bushland and their edge effects in Laikipia, Kenya. Ecological Applications 5:97-108.

Young, T. P., B. D. Okello, D. Kinyua, and T. M. Palmer. 1998. KLEE: a long-term multi-species herbivore exclusion experiment in Laikipia, Kenya. African Journal of Range \& Forage Science 14:94-102.

Young, T. P., T. M. Palmer, and M. E. Gadd. 2005. Competition and compensation among cattle, zebras, and elephants in a semi-arid savanna in Laikipia, Kenya. Biological Conservation 122:351-359.

Young, D., H. L. Perotto-Baldivieso, T. Brewer, R. Homer, and S. A. Santos. 2014. Monitoring British upland ecosystems with the use of landscape structure as an indicator for stateand-transition models. Rangeland Ecology and Management 67:380-388.

Young, T. P., L. M. Porensky, C. Riginos, K. E. Veblen, W. O. Odadi, D. M. Kimuyu, G. K. Charles, and H. S. Young. 2018. Relationships between cattle and biodiversity in multiuse landscape revealed by Kenya Long-Term Exclosure Experiment. Rangeland Ecology and Management 71:281291.

\section{SUPPORTING INFORMATION}

Additional supporting information may be found online at: http://onlinelibrary.wiley.com/doi/10.1002/eap.1982/full

\section{Data Availability}

Associated data are available on Figshare: vegetation cover by species, https://doi.org/10.6084/m9.figshare.8862143; vegetation cover by functional group, https://doi.org/10.6084/m9.figshare.8862140; and number of dung piles, https://doi.org/10.6084/m9. figshare. 8859623 . 